\title{
SOCIAL MARKETING: THE LIFEBLOOD OF BLOOD DONATION?
}

\author{
John Healy, Cork Institute of Technology, Ireland \\ Maurice Murphy, Cork Institute of Technology, Ireland
}

\begin{abstract}
In today's society, blood donation is dependent on the goodwill of people to voluntarily donate blood without financial reward. There is a continuous need for new blood donors, because the demand for donor blood is increasing, whereas the supply of blood is declining. Three thousand blood donations are needed in the Republic of Ireland every week. Maintaining an adequate supply is the biggest challenge. Only 3.6\% of the eligible population in the Republic of Ireland donate blood. This leaves an enormous potential blood donor base, which if tapped into and maintained could lead to an adequate reserve of donations to meet the transfusion needs of Ireland (Harrington et al. 2007). Research results from the Council of Europe (Van der Poel et al. 2007) found that the average number of donors in relation to the general population in Europe is 25 per 1,000 inhabitants. Ireland is slightly above this with 29.7 donors per 1,000 inhabitants. Repeat donors are the key individuals to maintaining a safe and sufficient blood supply (Schreiber et al. 2003), which is paramount as one in four individuals will require a blood transfusion at some stage in their lives (IBTS, 2007). Glynn et al. (2002) have identified several motivators for blood donation including altruism, awareness of the need for blood in the community, a sense of social obligation or duty, personal social pressure, the need to replace blood used by a friend or relative, and increased self esteem. Various reasons have been cited for avoiding blood donation. Fears about the collection process are the most prevalent (Gillespie and Hillyer, 2002). These include fear of needles, general apprehension, negative feelings about the sight of blood, concern about pain or bruising and anxiety that mistakes could be made during donation. Fear of adverse physiological reactions such as weakness or fatigue, dizziness, nausea, or fainting complicate the blood collection process, and are a significant disincentive for repeat donation (France et al. 2005). Kolins and Herron, (2003) propose that the way forward to achieve growth in blood donor numbers lies with a market-type approach with targeted marketing campaigns to profiled young people.
\end{abstract}

The main research question in this paper is to ascertain what social marketing advertising messages should contain in order to increase the supply of blood among young donors and non-donors. The specific research objectives were as follows: (1) What is the level of awareness of blood, the blood donation process and the importance of blood among young people? (2) What are the motivations/beliefs/expectancies of donors/non-donors? (3) What needs to be done to encourage blood donation among this group? (4) Are emotional-based advertisements more effective than rational appeal based advertisements? Seven focus groups were conducted during March 2010 among young people at a university in Cork, Ireland. College students were chosen due to their life-time value to the blood donation process. The students were chosen using a convenience sample. Focus groups consisted of a mixture of donors and non-donors. Participants were asked about their level of knowledge of the blood donation area and were then shown twelve television advertisements encouraging donation. Seven interviews were also conducted for the purposes of this research between January and April 2010. The interviews were held with leading personnel from the Irish Blood Transfusion Service (IBTS) and the Northern Ireland Blood Transfusion Service (NIBTS).

This paper reveals that altruism is still the biggest reason why young people donate blood. These people have high pro-social motives, having been encouraged to donate blood by their parents and friends. The key role of donors as recruitment agents for the blood sector is highlighted. For donors, donating blood is an intrinsic motivation and any attempt to compensate donors for this donation should be avoided. Advertisements that this segment found effective were ones that stressed the altruistic nature of donating blood. Non-donor participants were unaware of the whole area of blood and were not aware of its uses or the process of donation. This extended from a lack of knowledge of what their own blood type was, to where they could donate. They were characterised by complacency regarding possible blood shortages and a lack of knowledge of blood that blood organisations should find worrying, as they assumed that blood would always be available. The advertisements that they found effective to potentially alter behaviour, were the rational-based fear advertisements that challenged their excuses and their complacency and urged them to donate. Blood service organisations should target the youth segment (donors and non-donors) as they represent the future of blood donation due to their life-time value and potential to donate blood. They also have high pro-social tendencies. Advertising alone can not increase blood donation and waiting times, queues, location of fixed clinics and promotion of mobile blood clinic visits were all still cited as pivotal factors to increase donation. This will all aid in the recruitment, reward and retention of blood donors.

References available upon request 